\title{
Implementing Knowledge Management in Higher Educational Institutions in India : A Conceptual Framework
}

\author{
Mamta Bhusry \\ Ajay Kumar Garg Engineering College \\ 27 km Stone, Hapur Bypass Road, Adhyatmik \\ Nagar \\ Ghaziabad - 201009 \\ India
}

\author{
Jayanti Ranjan \\ Institute of Management Technology \\ Raj Nagar \\ Ghaziabad - 201001 \\ India
}

\begin{abstract}
Higher educational institutions (HEIs) create and apply knowledge during their processes and activities. The growth in the number of HEIs in India in the last decade has increased competition and the pressures for performing better. This has forced the institutions to recognize the need for knowledge management (KM) initiatives which is a key asset.

The purpose of the paper is to emphasize the need for knowledge management in higher educational institutions and to examine the impact of information technology (IT) based KM intervention. The paper explores the various the functional domains in HEIs and the indicators that determine these domains. The authors have evaluated the functional domains for IT based KM intervention and identified the perceived benefits. In order to reinforce the results, the authors have proposed a conceptual framework for the efficient capture, encapsulation, structuring, dissemination and employment of the organizational knowledge towards the organizational goals and objectives. If the framework is implemented, the authors feel it will result in enhanced transformation of organizational knowledge into decision making and actions.
\end{abstract}

\section{General Terms}

Knowledge Management, Higher Educational Institutions

\section{Keywords}

Knowledge, knowledge management, higher education, knowledge creation, knowledge encapsulation, knowledge structuring, knowledge dissemination

\section{INTRODUCTION}

A knowledge management approach is the conscious integration of people, processes and technology involved in designing, capturing and implementing the intellectual infrastructure of an organization [16]. It enables the people within an organization to share what they know, leading to improved services and outcomes. KM plays an important role in the improvement of organizational competitive advantage through sharing of best practices, achieving better decision making, faster response to key institutional issues, better process handling and improved people skills. In turn this means less reinvention of the wheel, relevant and focused policies in compliance with institutional goals and objectives, the ability to access information more quickly, improved academic and administrative services, reduced costs and prevention of mistakes and failures. In practice however few HEIs achieve all or even most of these benefits. The apparent failure in KM initiatives is primarily caused due to lack of sharing culture, lack of awareness of the benefits of $\mathrm{KM}$ and a failure to integrate $\mathrm{KM}$ into everyday working practices.

The colossal growth in the number of higher educational institutions in India in the last decade has stressed the institutions with the extreme pressures of competition and the need to perform better. HEIs consist of a number of academic and administrative processes that produce knowledge during their activities. The question is what value is added to the products and services they deliver by the effective use this knowledge asset [11]. The HEIs have to attune themselves to develop strategies for the utilization of the institutional knowledge towards enhancing their activities and performance. This requires them to respond timely to the dynamic technologies and the increasing demands of academia [12]. For this, the knowledge in the organization needs to be identified, encapsulated, transformed and disseminated effectively. This paves the way to recognize the urgent need for knowledge management initiatives which is a key asset. The application of a KM approach will enable institutions to gain a more comprehensive, reflexive and integrative view of the institutional knowledge for application in cross functional issues - ultimately leading to improved knowledge sharing and more effective decision making, planning and enhancement in performance.

The rest of the paper is organized as follows: Section 2 presents the related and other published work in the field. Section 3 is based on an overview of knowledge management. Section 4 emphasizes the need for knowledge management in higher educational institutions. Section 5 discusses the research methodology adopted and the inferences drawn. Section 6 proposes the KM framework for higher educational institutions in India. Section 7 summarizes the benefits and implications of the proposed framework. Section 8 ponders over the challenges and threats that the implementation of the framework will face. Section 9 explores the scope of the framework in cross functional and cross organizational environments. Section 10 concludes the paper. 


\section{RELATED WORK}

Significant work has been accomplished in the area of KM in higher educational system and many new contributions have been made by the researchers in this field.

[10] discussed why KM is vital to higher education systems and how an institution wide approach to KM can lead to exponential improvements in knowledge sharing - both explicit and tacit and the subsequent surge benefits. The work helped us to understand the benefits of various knowledge management applications on educational institution processes such as research, curriculum development, student and alumni services, administrative services and strategic planning.

In order to build and develop a robust and thriving knowledge environment, the institutes need to look beyond technology and develop the overall culture of accessing, sharing and managing knowledge [18]. The paper facilitated us to understand the role of technology as well as knowledge sharing culture towards developing a robust $\mathrm{KM}$ system in organizations.

[23] presented the KM multi-modeling framework to propose four organizational strategies for higher education - culture, leadership, technology and measurement and three academic KM strategies - individual, institutional and network. The paper guided us on the need for a blend of organizational and KM strategies for a robust knowledge management system.

[8] demonstrated the relevance of problem solving and decision making theory in assessing the purpose of organizational KM activities. The work helped us to understand the importance of problem solving and decision making for conceptualizing KM practices.

According to [1], IT based $\mathrm{KM}$ interventions seem to be promising techno-management tools to help cast an impact over all the vital areas of Indian higher education system. The research guided us to understand the urgent need for IT based $\mathrm{KM}$ intervention in higher educational institutions.

[12] concluded that in order to apply KM, knowledge and expertise must be readily accessible, understandable and retrievable. The paper helped us to understand the importance of efficient accessibility of institutional knowledge for effective knowledge management.

A KM system in higher educational institutions is necessary to identify, capture, transform, consolidate, evaluate and disseminate the institutional knowledge [20]. The paper helped us to identify the important phases in the proposed KM framework.

$\mathrm{KM}$ challenges lie in the creation of a knowledge environment and the recognition of knowledge as intellectual capital [19]. The paper helped us to understand that effective KM in higher education requires significant change in the culture and values, organizational structures and reward systems

[3] discussed the critical success factors for KM implementation in organizations. The study of the paper helped the authors to take into consideration the factors that influence the KM implementation in developing their framework.

[16] discussed the benefits that knowledge management practices can provide to organizations. The paper guided the authors on the need for implementing knowledge management in higher educational institutions.

This paper is motivated by the above related research to explore perception of stakeholders for IT based KM intervention in higher educational institutions. Based on the outputs, the authors have developed a KM framework that facilitates the institutions to capture, structure and disseminate the institutional knowledge so that it is readily available to everyone - anytime, anywhere.

\section{KNOWLEDGE MANAGEMENT}

Knowledge management is the discipline of enabling individuals, teams and entire organizations to collectively and systematically create, share and apply knowledge to better achieve their objectives. KM delivers outstanding collaboration to maximize the value of organizational information and knowledge assets leading to improved effectiveness and greater innovation.

[22] defines knowledge as "the insights, understandings and the practical know-how that we all possess". [15, 21,24] identified two types of knowledge - tacit and explicit. Tacit knowledge is the form of knowledge that is subconsciously understood and applied. Tacit knowledge is highly personalized, gained through experience and influenced by beliefs, perspectives and values of the individuals. It is difficult to codify and resides in the minds of the people possessing it. It is usually shared through highly interactive conversation and shared experiences. Explicit knowledge, on the other hand, is easy to articulate, capture and distribute in different formats. It is formal and systematic [13]. Explicit knowledge can be documented and easily communicated. This knowledge is easier to share and use across the organization.

Knowledge management systems are employed by organizations to meet the organizational objectives of improved performance, competitive advantage, experience transfer and the development of collaborative practices. [5] defines knowledge management as the "identification, growth and effective application of an organization's critical knowledge". Knowledge management is "the systematic, holistic approach to the sustainable improvement of the handling of knowledge on all levels of an organization" [6]. According to [13], knowledge management is the process of identifying, growing and effectively applying an organization's existing knowledge in order to achieve the organization's goals, while creating an organizational culture that permits further knowledge creation. From these and other views about knowledge management it is inferred that a good knowledge management system should be integrated into the daily routines of the people enabling a continuous knowledge flow in the organization.

A knowledge management system is based on capturing, storing, transforming and sharing the organizational knowledge. Information technology (IT) is a key enabler for KM systems and facilitates the capture, storage, transformation and dissemination of knowledge. 


\section{ROLE OF KM IN HIGHER EDUCATION IN INDIA}

Higher education institutes create knowledge during their academic and administrative processes. Knowledge is created as explicit knowledge in the form of documents, procedures, results as well as tacit knowledge in the form of experiences, judgements, views and perceptions that resides with individuals. The challenge is how to make available to the institution this explicit and tacit knowledge as an integrated central resource. Capturing and making the institutional knowledge available will ensure continuity and will accelerate institutional learning [16]. On the contrary, most HEIs face the difficult task of integrating their institutional knowledge for improved knowledge sharing and effective decision making.

Knowledge is created at various levels in different forms and is required at each level in a different form. Academic and administrative processes of teaching, examination, evaluation, admissions, counseling, training and placement and research and consultancy result in many useful experiences and studies which may be defined as knowledge in the context of higher educational institutes [18]. KM in higher educational institutions aims at integrating the knowledge produced at all levels and using it towards the institute's goals and targets. This will have the implications of improving the operational quality, capacity development and effectiveness of the organization leading to enhanced productivity and performance.

An academic institution is made up of a number of components or levels consisting of faculty, students, administration, academics, research and training and placement. Each of these levels creates knowledge as well as consumes knowledge, though the nature of knowledge varies at each level. It is important to identify the knowledge that each level contributes to the system and the knowledge that each level requires to perform its functions, and find ways to apply this knowledge effectively at the points of use. A robust KM system must adhere to the information needs of all the levels.

\section{RESEARCH METHODOLOGY}

\subsection{Identification of the Domains and Determinants}

The authors identified the functional domains in the HEIs and the determinants that support the effectiveness of KM in these domains via an interview and group discussion based study as well as professional experience in educational institutions. Inputs were also gathered from work already accomplished in the field of KM in higher education [1, 18].

Data on the functional domains in HEIs and the indicators that determine the domains was collected on the basis of information collected during group and individual interviews with the faculty, heads of departments, deans and staff and observations of the procedures and processes. The data collected was analyzed using the content analysis technique. Content analysis consists of analyzing the contents of documentary materials (books, magazines, newspapers) and verbal materials (interviews, group discussions) for the identification of certain characteristics that can be measured or counted.
The content analysis resulted in the identification of the activity domains in higher educational institutions and the determinants for KM intervention in these domains. The major domains were identified as institutional planning and development, research and consultancy, administrative services, purchase and procurement, finance and accounts, teaching and learning process, examination process, admission process, placements and faculty recruitment, faculty performance evaluation, student affairs and others. The authors restricted their study to only some specific domains.

\subsection{Qualitative Research and Pilot Study}

A study was conducted by the authors in the form of a survey from faculties and staff of reputed engineering colleges and business schools. The objective was to study the perceived importance attributed by stakeholders to IT based KM intervention in HEIs in order to establish a support for structured knowledge management. Based on the activity domains in HEIs and the determinants perceived to impact $\mathrm{KM}$ intervention in these domains, a questionnaire was framed. It consisted of a brief introduction on the purpose of the research specifying the authors' interest in the participants' perception of the impact on KM intervention in the functional domains of HEIs. The questionnaire was designed to be simple, easy to fill, less time consuming and focused. It consisted of three sections - the first on the demographic data like age, gender, educational qualifications, professional experience and other work responsibilities of the faculty. The second section consisted of the list of determinants in various domains to be evaluated by the faculty for KM intervention. The third section focused on collecting the views of the respondents on the perceived benefits that IT based KM intervention can have in the various functional domains.

To conduct the survey, the questionnaire was distributed to the respondents partly by mail and partly in person. The candidates for the survey consisted of senior faculty members, Deans, Heads of Departments, training and placement officer, administrative staff and section in charges. The selection of the respondents was done very carefully keeping in mind the nature of the institutions, academic qualifications, designations and professional experience. They consisted of participants with varied educational and cultural backgrounds, professional experience and exposure to varied learning experiences. The respondents were chosen from universities, engineering colleges and business schools in the NCR of Delhi. The names of the HEIs and the respondents have not been disclosed.

Follow up telephone calls and e-mails were made to remind the respondents that the survey should be completed in order to maximize the response rates. It took about one month to complete the survey wherein 167 responses were received out of a total of 550 forms distributed. The response rate of the survey was $30.36 \%$.

In answering the questionnaire, the respondents marked a determinant "YES" in support of KM intervention, else it was marked "NO". The responses were encoded, entered into the computer and results computed in the form of percentage response (YES / NO) for each determinant. These results are illustrated in appendix 1. Results have been shown only for some domains. 
The subjective questions in the questionnaire facilitated to collect the views of the respondents on the impact that KM intervention can have in the various domains. The conclusions are illustrated in table 1.

\subsection{Observations and Inference}

It was found that the importance given to the determinants for $\mathrm{KM}$ intervention differed from institution to institution depending upon the organizational structure, goals and targets, organizational responsibilities, stakeholders and the decision making authority. The results of the study assert the opinion that $\mathrm{KM}$ initiatives can play an important role in enhancing the performance and effectiveness of HEIs in their major work domains.

Table 1 : Impact of KM Intervention on Functional Domains

\begin{tabular}{|c|c|c|}
\hline Domain & & Impact of KM Intervention \\
\hline Planning and Development & $\begin{array}{l}\circ \\
\circ \\
\circ \\
\circ\end{array}$ & $\begin{array}{l}\text { Establishment and measurement of goals, objectives and } \\
\text { targets } \\
\text { Development of more relevant and focused policies } \\
\text { Increased consistency in decision making } \\
\text { Focus of strategic planning efforts towards institutional goals } \\
\text { and objectives } \\
\text { Improved procedures and processes } \\
\text { Standardization and effort towards total quality } \\
\text { management(TQM) }\end{array}$ \\
\hline Research & $\begin{array}{l}\circ \\
\circ \\
\circ \\
\circ \\
\circ \\
0 \\
0\end{array}$ & $\begin{array}{l}\text { Enhanced research } \\
\text { Motivation for research } \\
\text { Facilitation for inter disciplinary research } \\
\text { Utilization of institutional resources and facilities } \\
\text { Reduced time for research } \\
\text { Reduced costs } \\
\text { Easy access to research grants and facilities }\end{array}$ \\
\hline Placement Services & $\begin{array}{l}0 \\
\circ \\
0 \\
0\end{array}$ & $\begin{array}{l}\text { Better placements and higher average salaries } \\
\text { Enhanced planning for placements } \\
\text { Better long term association with corporates and companies } \\
\text { Improved guidance for placements }\end{array}$ \\
\hline Teaching and Learning Process & $\begin{array}{l}\circ \\
\circ \\
\circ \\
\circ \\
\circ \\
\circ\end{array}$ & $\begin{array}{l}\text { Effective teaching and learning process } \\
\text { Better and modern teaching methodologies } \\
\text { Improved student projects } \\
\text { Improved relevance of courses for industry practices } \\
\text { Motivation towards research in selected areas } \\
\text { Improved results }\end{array}$ \\
\hline Performance Evaluation of Faculty & $\begin{array}{l}\circ \\
\circ \\
\circ \\
0 \\
0\end{array}$ & $\begin{array}{l}\text { Enhanced support to retention and promotion } \\
\text { Better succession planning implementation } \\
\text { Enhanced plans for faculty development, training programs } \\
\text { and QIPs } \\
\text { Self Improvement and career development plans } \\
\text { Motivation towards superior performance } \\
\text { Assignment of the right people to the right jobs } \\
\text { Clear understanding of responsibilities and expectations } \\
\text { Fair grant of recognition, awards and compensation }\end{array}$ \\
\hline Administrative Services & $\begin{array}{l}\circ \\
\circ \\
0 \\
0\end{array}$ & $\begin{array}{l}\text { Improved effectiveness and efficiency of the administrative } \\
\text { services } \\
\text { Improved compliance with policies, goals and objectives } \\
\text { Enhanced responsiveness and accountability } \\
\text { Reduced process cycle times } \\
\text { Efficient decision making }\end{array}$ \\
\hline Student Affairs & $\begin{array}{l}0 \\
0\end{array}$ & $\begin{array}{l}\text { Improved availability and accessibility of institutional } \\
\text { resources to students } \\
\text { Enhanced services offered to students } \\
\text { Improved service capability of concerned staff and faculty }\end{array}$ \\
\hline
\end{tabular}


Based on the results of the survey, the authors emphasize the pressing need for KM intervention in HEIs. In order to facilitate this, the authors have proposed a conceptual framework for implementing knowledge management in higher educational institutions.

\section{PROPOSED FRAMEWORK}

The framework comprises of determining the existing gap in the knowledge needs of the organization and proposes an iterative process for closing the gap. It focuses on the identification of the strategic needs of the higher educational institutes based on the organizational goals and objectives, organizational hierarchical structure, stakeholders and the processes. Once this has been achieved it is important to determine the degree of the existing $\mathrm{KM}$ in the organization- what and how much useful knowledge is efficiently captured and reused in the forms required. The next step is to determine the knowledge gap and the factors that create this gap. The need is to close the gap for the efficient use of organizational knowledge towards goals and objectives.

The principal knowledge sources in higher educational institutes are the faculty, students, section heads, staff, administration, registrar and the training and placement services. They create tacit and explicit knowledge in the areas of academics, development and planning as a result of the activities performed.

The organizational knowledge is captured and encapsulated to be stored as a central institutional resource for use by all stakeholders. The storage of knowledge is facilitated by a central knowledge base called the knowledge repository. A knowledge repository is a structured collection of the knowledge generated in an organization. This includes the documents generated and the tacit knowledge available with the stakeholders, explicitly codified. The knowledge repository ensures the availability of related knowledge quickly and efficiently at the same place. The knowledge in the knowledge repository is mapped to different processes and disseminated to the users or stakeholders. [9] have discussed that storing knowledge in a central repository ensures the following -

a) Maintenance of shared context, thus improving the means of exploration of knowledge.

b) Ease of access as the knowledge is well structured and available at a central place

c) Ease of transfer to and fro from the stakeholders and processes.

d) Enhanced validity of knowledge as only validated knowledge makes its way to the central storage.

e) Easy identification of the source of knowledge.

The stored knowledge is structured into appropriate forms based on the organizational goals, the knowledge needs of the stakeholders and the processes in the organization. This consists of transformation of knowledge and its mapping to the processes where it is applied. The next phase is of the dissemination of the knowledge to the points of use. The knowledge is applied to the production of products and services in the organization. An important phase in the framework is the audit and measure of the effectiveness of the phases of the framework. This can be achieved through efficient feedback mechanisms. 


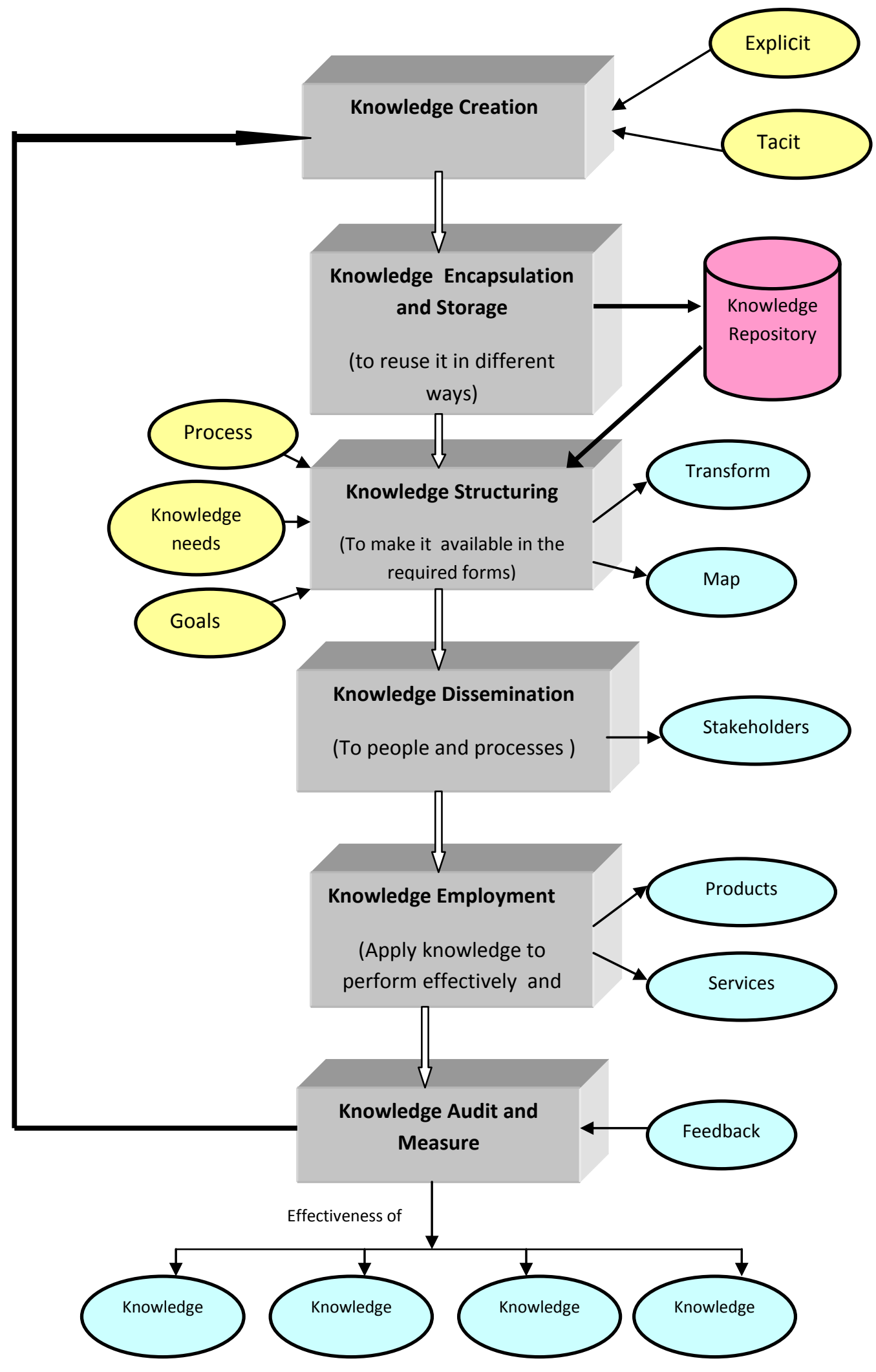

Figure 1 : The Knowledge Management Framework 
The application and use of knowledge creates more knowledge that needs of knowledge produces more knowledge that needs to be captured. This is an iterative process.

\section{IMPLICATIONS}

The implications of implementing the proposed framework and the opportunities it offers to higher educational institutions, discussed throughout the paper, are summarized in this section. The challenge faced by most KM systems is the lack of ability to integrate the capture and transfer of actionable, articulated and explicit knowledge [4]. The framework focuses on the integrated collection of knowledge from all levels in the institution and its dissemination for application at the points of use. Retirements, resignations and restructuring of activities leads to the phenomenon of "knowledge drain", particularly the tacit knowledge that resides in the minds of the people. This results in loss of useful knowledge from the organization. The challenge in minimizing knowledge loss is the ability to identify the knowledge sources and the necessary measures to ensure knowledge retention and utilization [4]. The framework offers opportunities to institutes to grow from a individual level to a cross functional and cross organizational knowledge sharing culture. Storage of the organizational knowledge in the knowledge repository as a central resource results in the availability of knowledge anywhere, anytime. Past experiences and data on failures and mistakes, if captured and stored, help to apply corrective and preventive measures to the newer domains. A centralized approach towards storage of organizational knowledge provides opportunity for collaborative work environment leading to better products and services.

\section{CHALLENGES FACED}

The implementation of the framework in higher educational institutions will face challenges and threats on account of human nature, existing organizational hierarchy and infrastructural constraints. Resistance to change, lack of proactive commitment, silos mentality and lack of co-operation among professionals are traits of human nature that will pose a challenge to the implementation of the framework into services. According to [14], the employees and more importantly top management are not very committed to KM initiatives. Most people believe that knowledge is power and the fear of losing tacit knowledge is an important reason for the lack of knowledge sharing culture in organizations. The implementation of the framework into services consists of integrating the processes pertaining to different functions. This is a challenging job as it involves many people and processes, both internal and external to the organization. The conversion of the framework to an automated system for access to knowledge anywhere, anytime requires robust authentication techniques to avoid misuse of any information. Lack of IT awareness at some levels in the organization is a constraint on the IT based implementation of the framework. The pressures of productivity and deadlines result into limited attention span and hence low commitment to knowledge management systems. Lack of incentives to participate/collaborate for knowledge sharing is another factor that discourages people from putting in the right effort towards knowledge sharing.

The successful implementation of a knowledge management system demands urgency in overcoming the barriers. It is required to conduct a culture audit to analyze the reasons for unwillingness of the people to share knowledge proactively. The mindset of the people from "my knowledge" should definitely change to "our knowledge" [17]. Motivating users of a KM system to contribute their knowledge to the system is critical for the success of the overall KM initiative [7]. Implementation of IT training programs, KM deployment sessions and recognition for $\mathrm{KM}$ practices will contribute towards the success of knowledge management initiatives in higher educational institutes.

\section{FUTURE WORK}

The authors intend to apply the proposed framework for developing a comprehensive IT based KM system to implement knowledge management in higher educational institutions in India. The framework can be implemented on the organizational intranets. In the next phase, the system can be integrated with knowledge bases of the companies, affiliating bodies, other colleges, suppliers and service providers resulting in an integrated KM system for the benefit of all the stakeholders internal and external to the organization.

\section{CONCLUSION}

Today higher educational institutions need to be efficient to tackle problems from cross functional, cross organizational, ethical and cultural perspectives and equipped with tools to achieve excellence. For this they need to develop a thriving knowledge sharing culture and look beyond just technology to achieve their goals and objectives.

From the results of the survey as discussed in the paper the authors conclude that IT based KM intervention in HEIs can prove to be a promising techno management tool to enhance performance in the vital areas of teaching and learning, research and administrative services. Based on the results the authors have presented a conceptual framework for the development and refinement of knowledge management systems in higher educational institutions. The authors feel that if implemented, the framework will yield more benefits to improve the quality of knowledge sharing and use. The approach will enable higher educational institutes to proactively respond to the needs of the stakeholders and acquire enhanced capability to plan and develop.

\section{ACKNOWLEDGEMENT}

The authors are thankful to the Directors and Principals of the engineering colleges and business schools for permitting their faculty and staff to participate in the survey and contribute their viewpoint towards the study.

\section{REFERENCES}

[1] Ashish, Arun, 2006, "IT Based KM in Indian Higher Education System: Addressing Quality Concerns and Setting the Priorities Right", Journal of Knowledge Management Practice, vol.7, No.3

[2] Brown, J.S., Duguid, P., 2000, "The Social Life of Information" Harvard Business School Press

[3] Butler, T., Murphy, C., 2007, "Implementing Knowledge Management Systems in Public Sector Organizations : A Case Study of Critical Success Factors", available at $\leq$ csrc.lse.ac.uk/asp/aspecis/20070021.pdf> 
[4] Delen, D., Al-Hawamdeh, S., 2009, “A Holistic Framework for Knowledge Discovery and Management", Communications of the ACM June 2009, vol. 52, No. 6, pp. $141-145$

[5] Duffy, N., 1999,"Benchmarking Knowledge Strategy", Leveraging Knowledge for Business Performance1999:Knowledge in Action WITS Business School, Johannesburg

[6] Eppler, M.,2002, Glossary definition: Knowledge Management.Net Academy:www.knowledgemedia.org

[7] Frappaolo, C., 2006, "Knowledge Management", West Sussex: Capstone Publishing Ltd. 127

[8] Huveida, R., Shams, G., Hooshmand, A., 2008, "Knowledge Management Practices in Higher Education Institutes : A Different Approach", IEEE 978-1-42442917-2,pp. 695-702

[9] Kevin, C.D., Evaristo, J.B., 2004, "Managing Knowledge in Distributed Projects", Communications of the ACM, Vol. 47, No. 4 pp. 87-91

[10] Kidwell,J.,J., et al., 2000, "Applying Corporate Knowledge Management Practices in Higher Education", Educause Quaterly, pp. 28-33

[11] Milam, John H., Jr.,2001, "Knowledge Management for Higher Education", ERIC Digest ED464520

[12] Nagad, W., Amin, G., 2006, "Higher Education in Sudan and Knowledge Management Applications", IEEE 0-78039521-2/06, pp. 60-65

[13] Nakkiran, N.S., Sewry, D.A., 2002, "A Theoretical Framework for Knowledge Management Implementation", Proceedings of SAICSIT, pp. 235-245

[14] Nakkiran, N.S., 2001, "Knowledge Management for the South African Motor Vehicle Manufacturing Industry", Proceedings of South African Institute of computer
Scientists and Information Technologists Annual Conference

[15] Nonaka, I., 1998 , "Knowledge Creating Company", Havard Business Review on Knowledge Management, Havard Business School Publishing, BostonVol. 2004, Issue 20

[16] Petrides, L.A., 2004, "Knowledge Management, Information Systems and Organizations", EDUCAUSE Center for Applied Research, Research Bulletin,

[17] Ranjan, J., 2008, "Knowledge Management in Business Schools", Journal of Information and Knowledge Management, Vol. 7, No. 1, pp. 55-62

[18] Ranjan, J., Khalil, S., 2007, “Application of Knowledge Management in Management Education : A Conceptual Framework", Journal of Theoretical and Applied Information Technology, pp. 15-25

[19] Rowley, J., 2000, "Is Higher Education Ready for Knowledge Management", The International Journal of Educational Management, vol 14, No. 7, pp.325-333

[20] Sedziuviene, N., Vveinhardt, J., 2009. "The Paradigm of Knowledge Management in Higher Educational Institutions", Inzinerine Ekonomika-Engineering Economics(5), pp. 79-90

[21] Tiwana, A., 2000, The Knowledge Management Toolkit : Practical Techniques for Building a Knowledge Management System, Prentice Hall, New Jersey

[22] Wiig, K.M., 1996, "On the Management of Knowledge", available at http://www.km-forum.org/what_is.htm

[23] Yeh, C.M.Y., 2005, "The Implementation of Knowledge Management System inTaiwan's Higher Education", Journal of College Teaching and Learning, Vol.2, No.9, pp. $35-41$

[24] Zack, M.H., 1999,“Managing Codified Knowledge”, Sloan Management Review, vol. 40, no. 4, pp.45-59 


\begin{tabular}{|l|c|c|c|}
\hline \multicolumn{2}{|c|}{ Institutional Planning and Development } & Response in \% \\
\hline \multicolumn{1}{|c|}{ Determinants for KM Intervention } & Y-Axis Labels & YES \\
\hline $\begin{array}{l}\text { Institutional goals, objectives, vision, mission, targets and quality } \\
\text { policy }\end{array}$ & D1 & $93 \%$ & $7 \%$ \\
\hline $\begin{array}{l}\text { Plans and policies outlined by important functionaries of the } \\
\text { institute }\end{array}$ & D2 & $92 \%$ & $11 \%$ \\
\hline $\begin{array}{l}\text { Reports by review committees and accreditation bodies on the } \\
\text { compliance of the institute to norms }\end{array}$ & D3 & $89 \%$ & $13 \%$ \\
\hline reports on competitor data & & D4 & $22 \%$ \\
\hline data related to assessment of procedures and processes & D5 & $78 \%$ \\
\hline
\end{tabular}

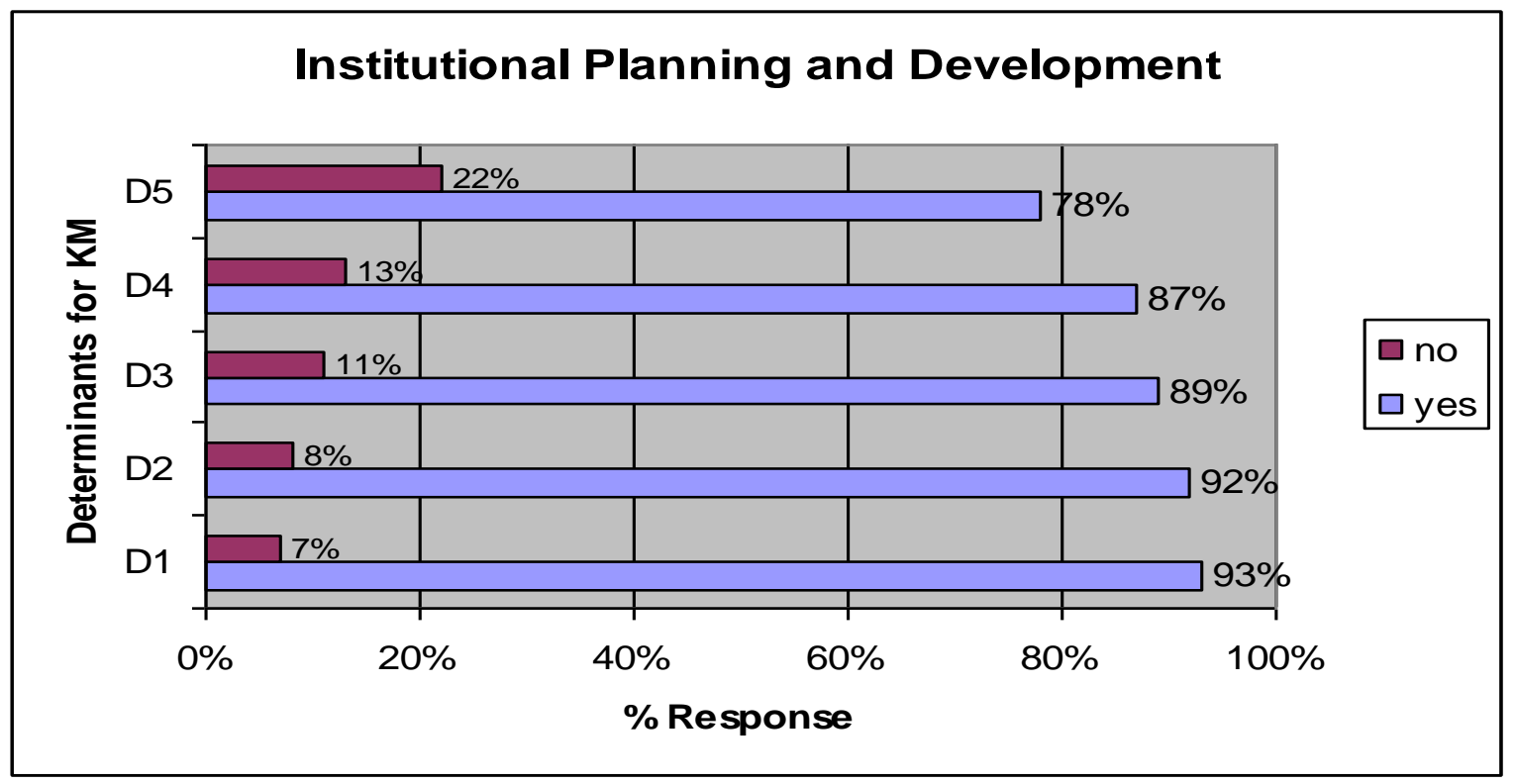

Figure 2 : Respondent acceptance to IT based KM in HEI Institutional Planning and Development

\begin{tabular}{|l|c|c|c|}
\hline \multicolumn{2}{|c|}{ Placement services } \\
\hline \multicolumn{1}{|c|}{ Response in \% } \\
\hline \multicolumn{1}{|c|}{ Determinants for KM Intervention } & Y-Axis Labels & YES & NO \\
\hline $\begin{array}{l}\text { Company data(salary packages, turnover, job profiles, promotion } \\
\text { policies) }\end{array}$ & D1 & $98 \%$ & $2 \%$ \\
\hline Industry trends & D2 & $94 \%$ & $6 \%$ \\
\hline
\end{tabular}




\begin{tabular}{|l|c|c|c|}
\hline Approved procedures and processes, forms and applications used & D3 & $76 \%$ & $24 \%$ \\
\hline Top recruiters & D4 & $72 \%$ & $28 \%$ \\
\hline Feedback from companies & D5 & $87 \%$ & $13 \%$ \\
\hline Nature of interview sessions & D6 & $89 \%$ & $11 \%$ \\
\hline Alumni data & D7 & $78 \%$ & $22 \%$ \\
\hline
\end{tabular}

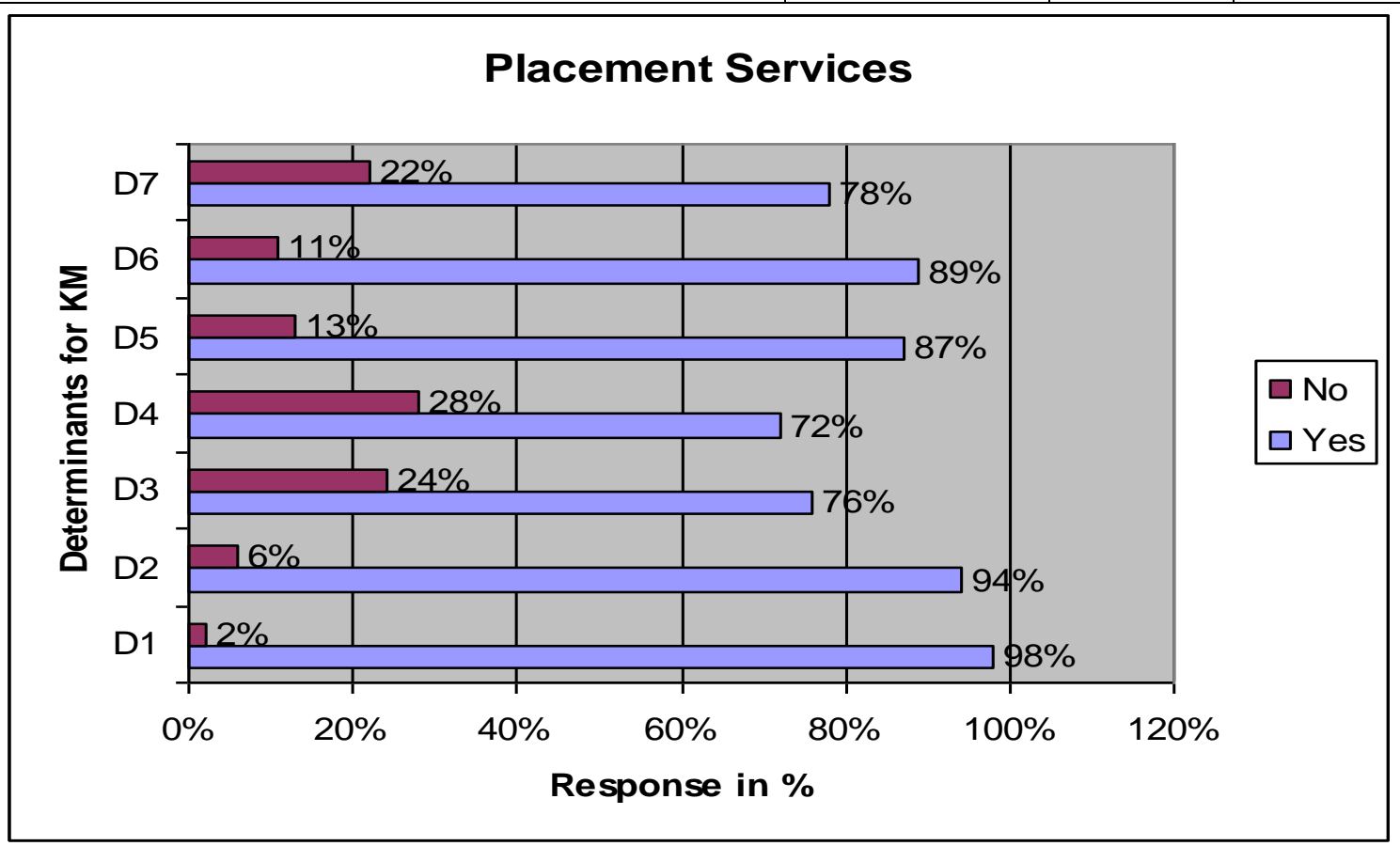

Figure 3 : Respondent acceptance to IT based KM in HEI Placement Services

\begin{tabular}{|l|c|c|c|}
\hline \multicolumn{2}{|c|}{ Institutional Teaching and Learning Process } & \multicolumn{2}{c|}{ Response in \% } \\
\hline \multicolumn{2}{|c|}{ Determinants for KM Intervention } & Y-Axis Labels & YES \\
\hline Teaching material prepared by the faculty & D1 & $92 \%$ \\
\hline Course plans - proposed and actual & D2 & $91 \%$ \\
\hline Curriculum & D3 & $98 \%$ & $2 \%$ \\
\hline Question banks, assignments and solutions, case studies & D4 & $88 \%$ & $12 \%$ \\
\hline Typical problems faced by faculty in a course & D5 & $90 \%$ & $10 \%$ \\
\hline Topics students find difficult to understand & & D6 & $10 \%$ \\
\hline Frequently asked questions(FAQs) & D7 & $80 \%$ & $11 \%$ \\
\hline
\end{tabular}




\begin{tabular}{|l|c|c|c|}
\hline $\begin{array}{l}\text { Effective teaching methodologies used by faculty for specific } \\
\text { topics }\end{array}$ & D8 & 93\% & $7 \%$ \\
\hline Related research & D9 & $87 \%$ & $13 \%$ \\
\hline Related projects & D10 & $87 \%$ & $13 \%$ \\
\hline Industry interfaces & D11 & $87 \%$ & $13 \%$ \\
\hline
\end{tabular}

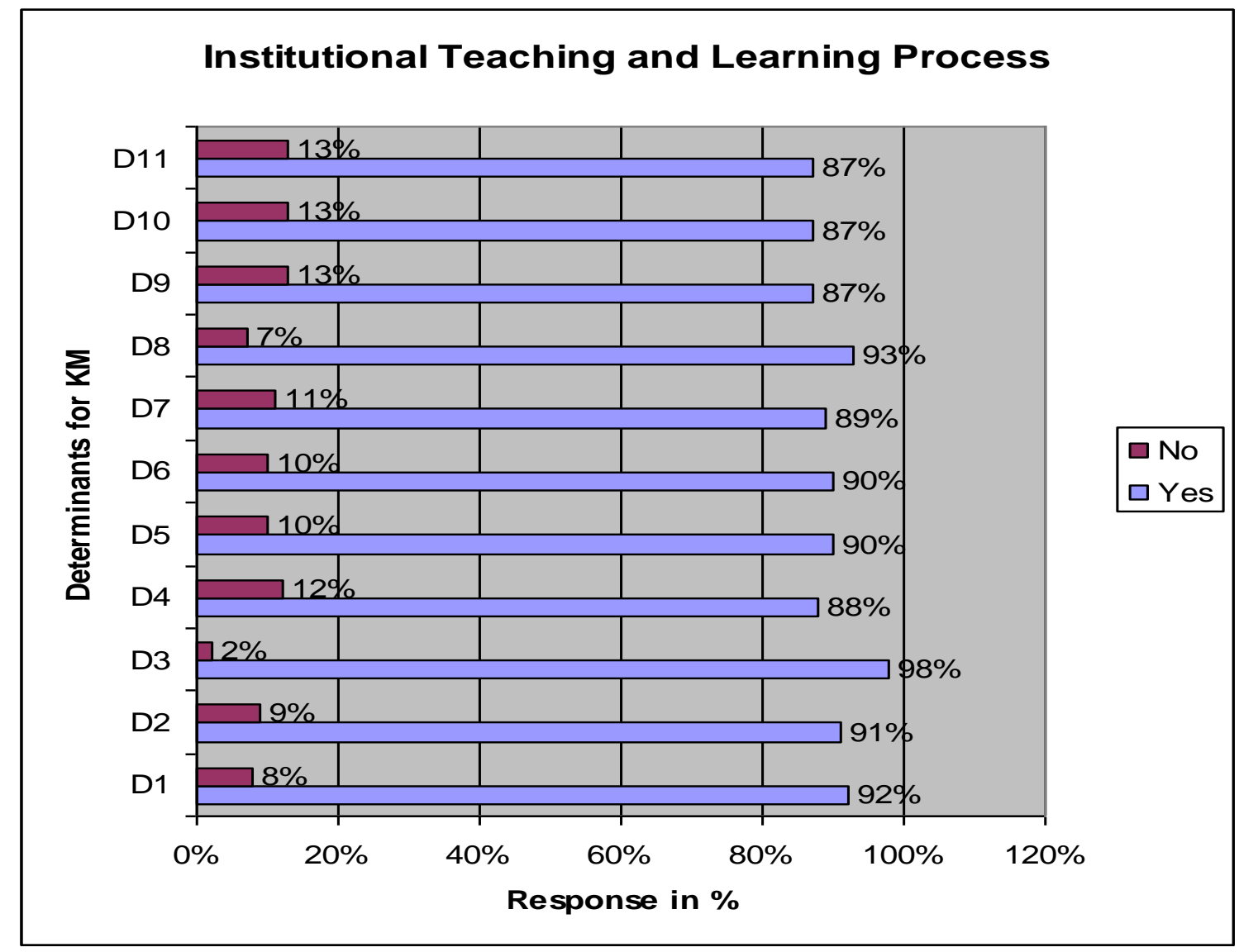

Figure 4 : Respondent acceptance to IT based KM in HEI Teaching and Learning Process

\begin{tabular}{|l|c|c|c|}
\hline \multicolumn{2}{|c|}{ Performance Evaluation of the faculty } & \multicolumn{2}{c|}{ Response in \% } \\
\hline \multicolumn{2}{|c|}{ Y-Axis Labels } & YES & NO \\
\hline Results in courses taught by faculty & D1 & $95 \%$ & $6 \%$ \\
\hline Research papers published by the faculty & D2 & $94 \%$ & $11 \%$ \\
\hline Industrial Consultancy and projects taken up by the faculty & D3 & $89 \%$ & $10 \%$ \\
\hline Student Projects guided by the faculty & D4 & $90 \%$ & \\
\hline
\end{tabular}




\begin{tabular}{|c|c|c|c|}
\hline Student feedback & D5 & $76 \%$ & $24 \%$ \\
\hline Peer rating & D6 & $78 \%$ & $22 \%$ \\
\hline $\begin{array}{l}\text { Seminars, workshops and conferences organized by the } \\
\text { faculty }\end{array}$ & D7 & $89 \%$ & $11 \%$ \\
\hline $\begin{array}{l}\text { Seminars, workshops and conferences attended by the } \\
\text { faculty }\end{array}$ & D8 & $81 \%$ & $19 \%$ \\
\hline Administrative responsibilities carried out by the faculty & D9 & $90 \%$ & $10 \%$ \\
\hline Personal Skills evaluation of the faculty & D10 & $83 \%$ & $17 \%$ \\
\hline Initiatives for self improvement and career development & D11 & $89 \%$ & $11 \%$ \\
\hline
\end{tabular}

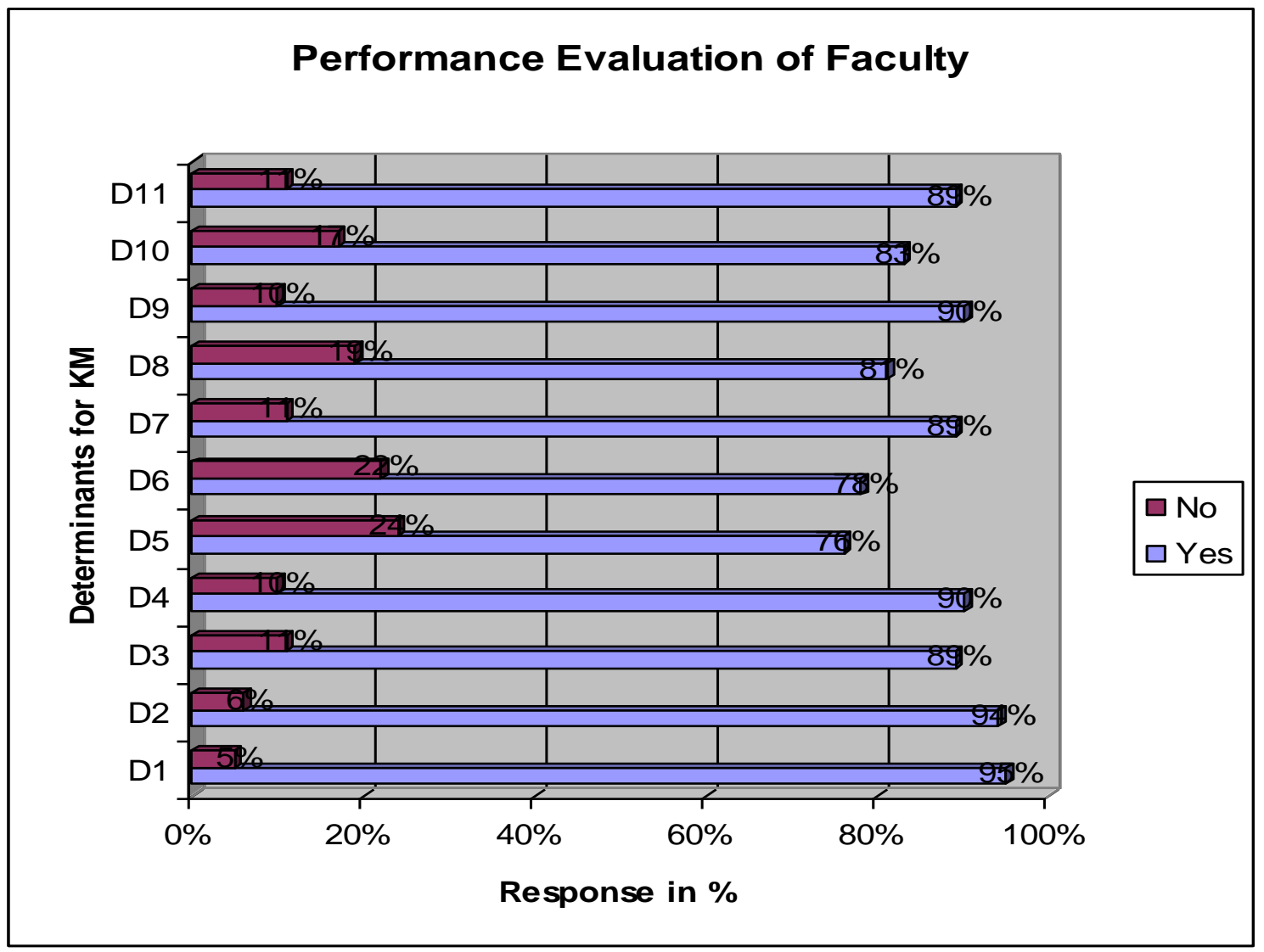

Figure 5 : Respondent acceptance to IT based KM Performance Evaluation of Faculty in HEIs

\begin{tabular}{|c|c|c|c|}
\hline \multicolumn{4}{|c|}{ Institutional Administrative Services } \\
\hline & & Res & \\
\hline Determinants for KM Intervention & Y-Axis Labels & YES & NO \\
\hline Procedures and formats of all forms and reports & D1 & $95 \%$ & $5 \%$ \\
\hline
\end{tabular}




\begin{tabular}{|l|c|cc|}
\hline Copy of academic and cultural schedules & D2 & $67 \%$ & $33 \%$ \\
\hline Rules and regulations & D3 & $92 \%$ & $8 \%$ \\
\hline HR policies for training and promotions & D4 & $94 \%$ & $6 \%$ \\
\hline Minutes of meetings & D5 & $94 \%$ & $6 \%$ \\
\hline
\end{tabular}

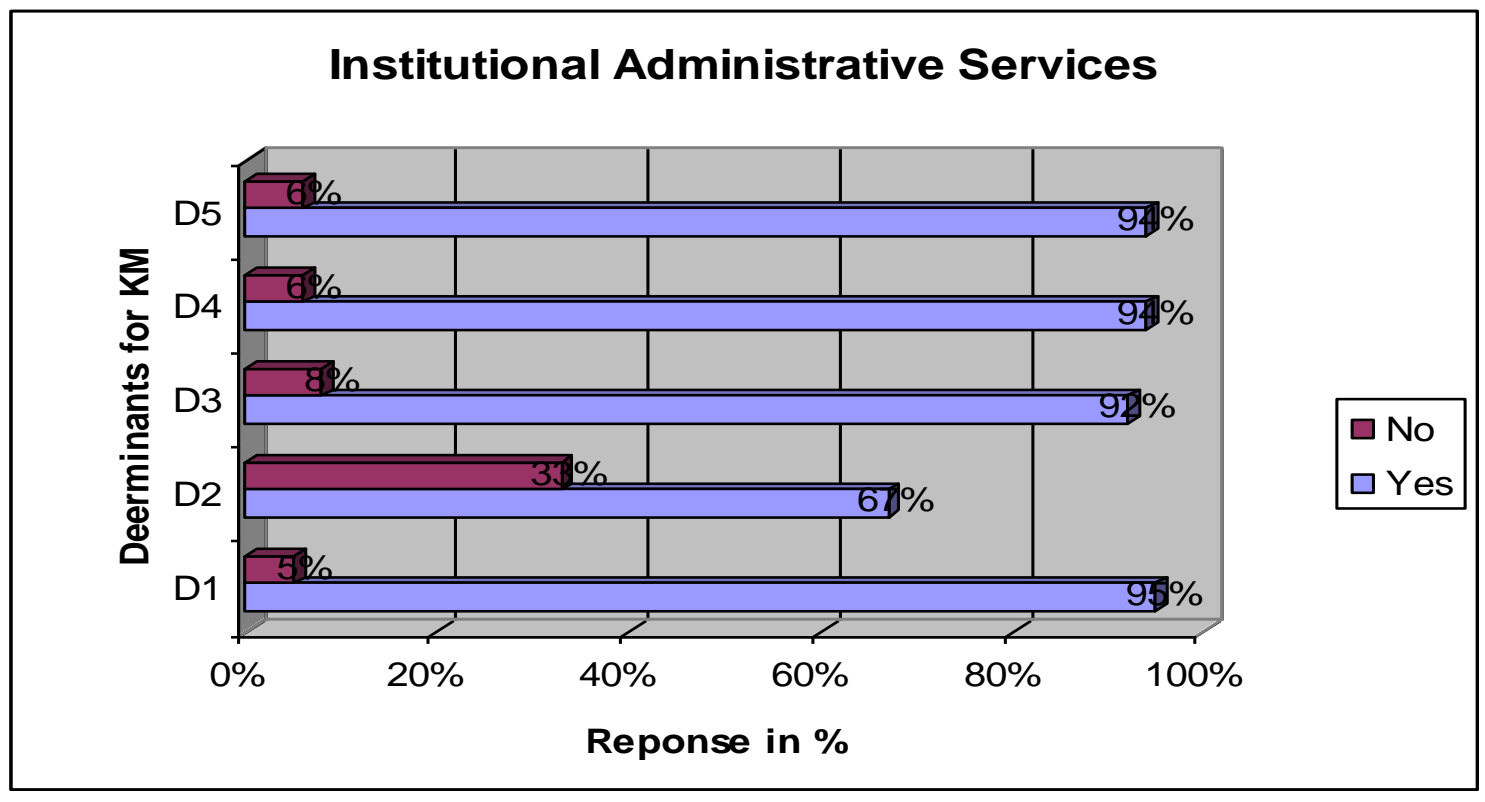

Figure 6 : Respondent acceptance to IT based KM in HEI Administrative Services 